\title{
A systematic review of using mobile devices in medical education
}

\author{
Laura Briz Ponce; Juan Antonio Juanes Méndez; Francisco José García Peñalvo \\ Research Institute for Educational Sciences \\ University of Salamanca \\ Salamanca, Spain. \\ laura.briz@usal.es,jajm@usal.es, fgarcia@usal.es
}

\begin{abstract}
There are many research studies carried out about the use of mobile devices in our society. Mobile devices offer great opportunities in different aspects of our daily routine as it enable people to be connected at any time. The increasing number of mobile devices and their use confirm that the new technologies are part of our lives. Not only that, medical professionals are starting to be involved actively in the use of mobile devices. This paper describes how students and medical professionals use mobile devices from an educational perspective and it investigates the roles of their involvement. To achieve this goal, we performed a crosssectional survey involving undergraduate medical students of University of Salamanca and medical professionals. The results confirm that the new technologies are becoming part of our lives and medical professionals are starting to be part of this upward trend.
\end{abstract}

Keywords-medical education; mobile devices; mlearning; mhealth; higher education

\section{INTRODUCTION}

According to Telecommunication Commission [1] in Spain, there are 50,6 millions of mobile lines. The rapid growth of mobile devices has sparked a huge rise in content applications. There are daily 4 millions of downloads of mobile applications. Smartphone has a media of 24 applications installed on it whereas tablet has 31 applications [2]. Because of that, there are many reports that carry out research studies about this issue and publish different patterns of mobile devices use.

The reference [3] indicates that a greater percentage of students in $2012(62 \%)$ than in $2011(55 \%)$ owned a Smartphone and nearly twice as many in 2012 (67\%) than in 2011 (37\%) reported using their Smartphone for academic purposes. If we analyze the data considering physicians, $90 \%$ of physicians accessed to internet during 2013 at least with two types of devices. Besides, $51 \%$ of them have used the Smartphone for accessing medical information [2].

Because of that, many higher education organizations are implementing mobile learning to provide flexibility in learning [4]. Not only that, if we specify more in detail, many Medical Schools have already introduced the tablets as a new tool for education [5] [6]. For example, at Stanford University's medical school all students are given an iPad to use in place of text books. The evidence shows that mobile devices have an evergrowing presence in medical education and the different results of the researches seem to suggest that teachers and students want to be prepared for the developing digital area [7]. The current educational model is outdated because it was developed before the advent of information and communication technologies [8].

The reference [9] examines the rapidly changing use of mobile technologies in healthcare professionals. This report comments that clinicians clearly endorse the viability of mobile technology to enable rapid access to clinical information and communication among them.

All these data demonstrate that the introduction of new technologies in medical industry is becoming a reality. Because of that, the goal of this study is a research approach to gauge the current use of mobile devices by students and medical professionals from a medical education perspective.

This paper is structured in four sections. The first section describes the methodology used for the survey carried out in Universidad of Salamanca. The second section describes the profile of the participants. The third section explains the main uses of mobile devices, what are the types of applications they use and the period of time they spend using them. The last section shows a discussion and conclusions drawn of this study.

\section{METHODOLOGY}

\section{A. Method}

The method used for this reseach is a survey distributed in two ways: face-to-face interview and on line procedure.

The face-to-face survey was distributed and collected directly to undergraduate medical students ten minutes before starting a class of the first course in the Medical School of Salamanca. In the case of medical professionals, the survey was distributed among personal contacts and collected one month later.

The on line survey was developed using Google Docs tool. The participants received an email with a link to a web survey. 
The front page of the survey explained the purpose of the survey in more detail, explaining that it is part of a doctorate programme. They responded to the survey anonymously, and the data were stored in the hosted online survey service.

The conducted survey was formed by 19 questions which covered the main participant's characteristics: gender, age, mobile devices ownership, daily use of Smartphone application and tablet applications, the most important issues for downloading mobile applications and the type of mobile applications downloaded by the participants.

The survey was open and data were collected from March 2014 to April 2014.

By the end of the survey period, data had been collected from 124 individuals. The collected data were computerized in the program SPPS 21 [10] and we use this tool to analyse the different variables obtained from the data [11].

\section{B. Participants}

The survey was conducted involving undergraduate students of Medical School in University of Salamanca and medical professionals. We involved medical residents, medical specialists and medical teachers in the group of medical professionals.

TABLE I. DESCRITPTIVE STATISTICS ON PARTICIPANT CHARACTERISTICS

\begin{tabular}{|c|c|c|c|}
\hline \multirow{2}{*}{ Variable } & \multicolumn{3}{|c|}{ Participants Characteristics } \\
\hline & Descriptive & Frequency & Percentage \\
\hline \multirow{2}{*}{ Gender } & Male & 45 & $36,3 \%$ \\
\hline & Female & 79 & $63,7 \%$ \\
\hline \multirow{4}{*}{ Profile } & Student & 61 & $49,2 \%$ \\
\hline & Medical Residents & 24 & $19,4 \%$ \\
\hline & Medical Specialists & 21 & $16,9 \%$ \\
\hline & Medical teachers & 18 & $14,5 \%$ \\
\hline \multirow{5}{*}{ Range Age } & From 18 to 25 years old & 60 & $48,4 \%$ \\
\hline & From 26 to 35 years old & 28 & $22,6 \%$ \\
\hline & From 36 to 45 years old & 6 & $4,8 \%$ \\
\hline & From 46 to 55 years old & 23 & $18,5 \%$ \\
\hline & +55 years old & 7 & $5,6 \%$ \\
\hline \multirow{4}{*}{ Ownership } & Only Smartphone & 58 & $46,8 \%$ \\
\hline & Only Tablet & 1 & $0,8 \%$ \\
\hline & Smartphone and Tablet & 58 & $46,8 \%$ \\
\hline & None & 7 & $5,6 \%$ \\
\hline
\end{tabular}

The Table I provides information of the survey participant's characteristics. The table shows the frequency and the percentage of each characteristic. As for the data, we have that the dominant age of the participants falls within the range from 18 to 35 years old with $71 \%$ of the participants.

Besides, we have over half of the participants were students $(n=61,49,2 \%)$, medical residents represents $19,4 \%$ of total $(n=24)$, medical specialists are $16,9 \%(n=21)$ and finally, the medical teachers who answered the survey were $14,5 \% \quad(n=18)$ which it means that the medical professionals represents the $50,8 \%$ of the total.

It is also important to stress that the most part of the participants (in fact, 94.4\%) reported they owned a Smartphone, a tablet device or of both of them.

\section{RESULTS}

\section{A. Mobile Applications Use.}

In this section, we are going to analyse how students and medical professionals use daily the mobile applications with their smartphone and/or their tablet. The Figure 1 shows that most part of the participants use these mobile devices and only 9\% of the participants that owned a Smartphone do not use them to download mobile applications.

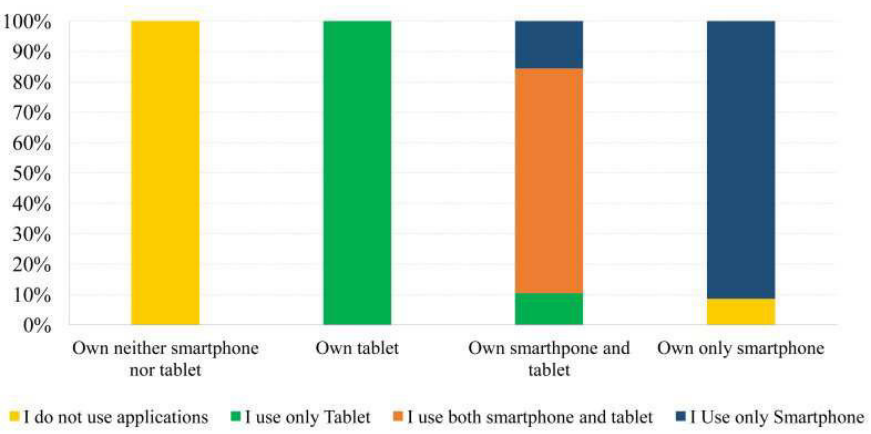

Fig. 1. Percentage of smartphone and tablet ownership and percentage of use downloading mobile applications.

\section{B. Mobile Applications Use.}

In the survey, we also asked the participants about the frequency they use Smartphone or tablet applications. We consider very important to differentiate between students and medical professionals to see if it exists any differentiation of the pattern of use among them, so we use box plot diagram in order to illustrate the spread and differences of samples. In this case, we can see the daily frequency samples obtained for each profile (students, medical residents, medical specialists and teachers).

The results obtained are set out in Figure2. From the chart, it can be seen that there are some differences among them. The median result for medical professionals is between one and two hours per day, less than the median for Students. In this case, the daily media is three or four hours. Besides, the chart shows that medical professionals have quite different opinions about this aspect as the box is comparatively tall. 


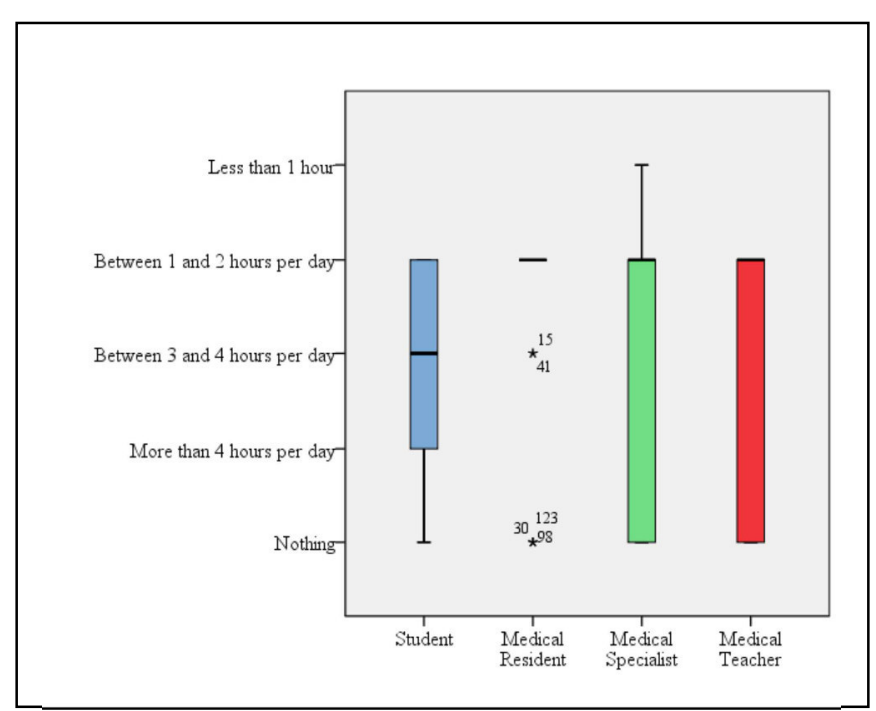

Fig. 2. Box plot Graphic: daily frequency for Smartphones

If we analyze the same data taking into account the daily use for tablets applications (Figure 3), the median is completely different from the figure 2 .

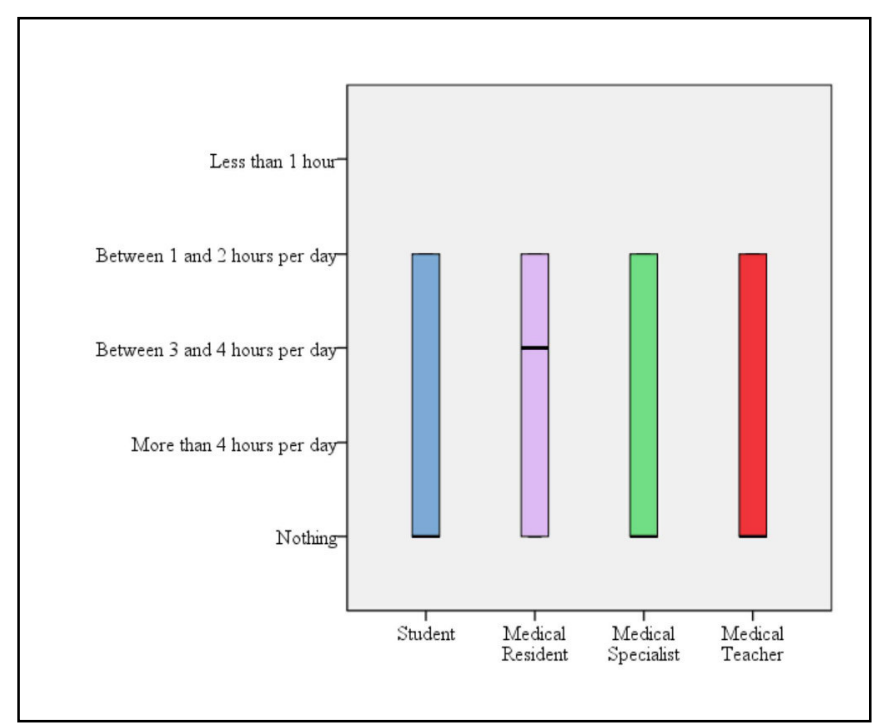

Fig. 3. Box plot graphic: daily frequency for Tablets

The most striking result of the Figure 3 is that students are not barely using tablets for downloading mobile applications, whereas the medical residents are the one that use more frequently the tablet per day. The results for medical specialist and for teachers are very similar to the one obtained with the Smartphone.
Now, we analyzed the dependency between these variables (daily use of applications with Smartphones and profiles of the participants). The null hypothesis attempts to show that there is no relationship between them. As they are nominal variables, it was necessary to use the non-parametric Chi-square method [12]. We considered two test variables as rows: the daily application time for Smartphone. As columns, we selected the profile of the participants (student, medical residents, medical specialists and medical teachers). The comparative results between frequency Smartphone use and profile of the participants are presented in Table II. In this case, we wanted to obtain the Chi-Square value and the phi and V'Cramer coefficient [13] as well.

TABLE II. RESULTS FOR CHI-SQUARE METHOD BETWEEN DAILY USE OF APPLICATIONS WITH SMATPHONES AND PROFILES OF THE PARTICIPANTS

\begin{tabular}{|l|l|l|}
\hline \multirow{2}{*}{ Chi-square } & Smartphones & p-value (sig) \\
\cline { 2 - 3 } & Value & 0,000 \\
\hline Phi & 71,012 & 0,000 \\
\hline Cramer's V & 0,757 & 0,000 \\
\hline
\end{tabular}

At the $\alpha=0,05$ level of significance, there exists enough evidence to conclude that we reject the null hypothesis that considers both variables independents $(p=0,000, p<0,05)$; besides, the values of Phi and Cramer's $\mathrm{V}$ falls within the range from 0,3 to 0,7 so it can be said that there is a moderate relationship between the daily use of the smartphones and the profile of the participants.

Now, we obtain the data for the comparative between the frequency tablet use and the profile of the participants. The data are set out in Table III.

TABLE III. RESULTS FOR CHI-SQUARE METHOD BETWEEN DAILY USE OF APPLICATIONS WITH TABLETS AND PROFILES OF THE PARTICIPANTS

\begin{tabular}{|l|l|l|}
\hline \multirow{2}{*}{ Chi-square } & Tablets & p-value (sig) \\
\cline { 2 - 3 } & Value & 0,120 \\
\hline Phi & 14,054 & 0,120 \\
\hline Cramer's V & 0,347 & 0,120 \\
\hline
\end{tabular}

At the $\alpha=0,05$, level of significance, this table tell us that there is statistically significant association between profile and frequency tablet use $(p=0,120, p>0,05)$; that is, there is no evidence enough to fail to reject the null hypothesis that both variables are independents. 


\section{Characteristics.}

The participants were asked about their opinion on the characteristics more important for downloading mobile applications. They could select more than one option, without limiting the maximum number of answers. The figure 4 shows the percentage of each characteristic chosen by the participants.

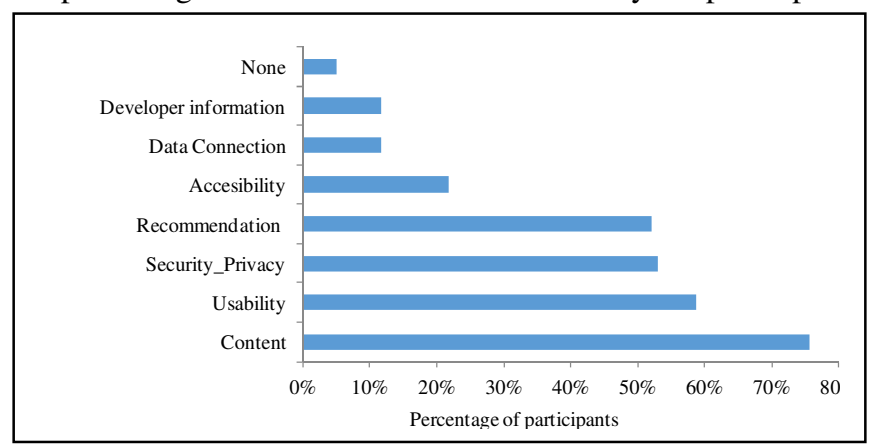

Fig 4. Most important characteristics for downloading applications.

As they can select more than one option, the sum of the percentages is not equal to $100 \%$. On average, each participant had selected 2,89 characteristics of 8 options they could choose.

We can see that the content feature is by far the most selected option, followed by usability. Over half of the participants hold the opinion that the recommendation of a friend or the security and privacy characteristic is important. We can obtain the samples categorized by participant's profile, therefore, we obtain the Figure 5

Several themes emerged from this analysis. First of all, the content is the characteristic that students, medical residents and medical teachers were selected the most. In fact, medical teachers consider by far this characteristic as the most important one. Medical residents consider the security/privacy and the content option as the same level of importance.

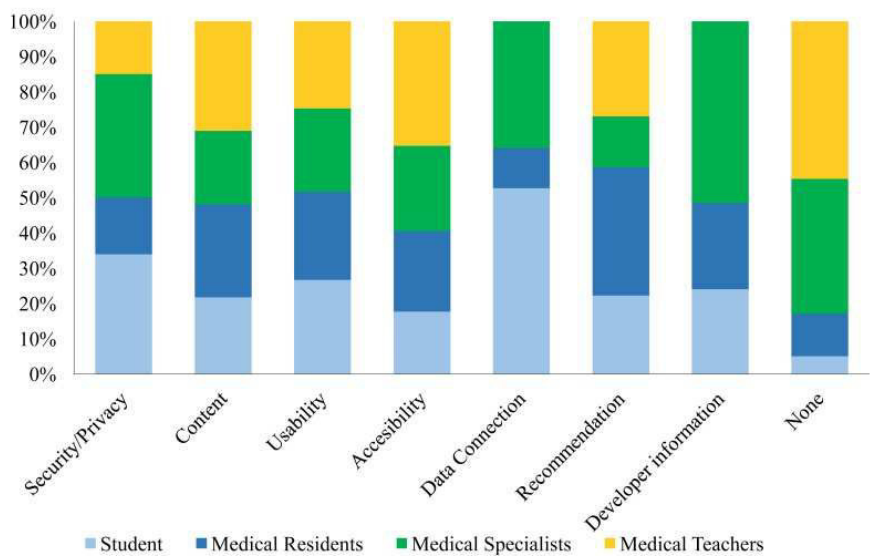

Fig 5. Most important characteristic for downloading applications divided by participants profile.
Recommendation from a friend is important for medical residents and medical teachers but for students this characteristic is not so relevant. Usability has similar results independently of the profile.

On the other hand, the survey included an open-ended question to give the participants the opportunity to suggest other options that were not included on the previous list. Of the 124 participants who completed this questionnaire, $83,9 \%$ of them did not indicate any other additional characteristic. A minority of participants $(4,8 \%)$ did not even answer it. The total number of responses for this question was very poor, but among the answers, we obtained that $6,5 \%$ of participants considered the price an important issue and $1,6 \%$ of them considered the capacity to storage in the mobile devices as important issue to take into account..

Finally, after selecting all the characteristics that they took into account to download applications, they should select only one of all of them. If we analyze the results, we can obtain that the ranking for the characteristics is presented inTable IV.

TABLE IV. FRECUENCY OF CHARACTERISTICS FOR DOWNLOADING APPLICATIONS

\begin{tabular}{|l|l|l|}
\hline & Characteristic \\
\cline { 2 - 3 } & Frequency & Percentage \\
\hline Content & 35 & $34,3 \%$ \\
\hline Security_Privacy & 29 & $28,4 \%$ \\
\hline Usability & 17 & $16,7 \%$ \\
\hline Recommendation & 10 & $9,8 \%$ \\
\hline None & 8 & $7,8 \%$ \\
\hline Accesibility & 1 & $1 \%$ \\
\hline Data Connection & 1 & $1 \%$ \\
\hline $\begin{array}{l}\text { Developer } \\
\text { information }\end{array}$ & 1 & $1 \%$ \\
\hline
\end{tabular}

From the Table IV it can be seen that the content was by the far the most important characteristic considered for the participants. If we now turn to the Figure 4, we can see that this characteristic was the most selected option as well.

\section{Type of Mobile Applications.}

Now we turn to analyse the type of mobile applications that the students and medical professionals use the most. Overall, these results describe if the students and medical professionals use applications with educational purposes, or medical applications, or other type of applications. It is important to highlight that we differentiate the mobile applications used for medical education (anatomical atlas, information, etc) and mobile applications use for medical aspects (as disease diagnosis, drug reference, patient care, medical calculators, etc). 
In this case, the results are shown in Table V. The applications most used are the ones related with entertainment, followed by social networks and games. The applications related with medicine: medical applications and the ones used for medical education, are at $5^{\text {th }}$ and $7^{\text {th }}$ place respectively.

The last column of the table $\mathrm{V}$ explains the percentage of participants that have selected this type of applications. For example, $71,5 \%$ of participants have chosen entertainment applications or medical applications has been selected by $33,5 \%$ of them and applications for medical education by $25,2 \%$. On average, each participant has selected 3,5 different categories of mobile applications.

TABLE V. TYPE OF MOBILE APPLICATIONS USED BY PARTICIPANTS

\begin{tabular}{|l|l|l|l|}
\hline \multirow{2}{*}{} & \multicolumn{2}{|l|}{ Responses } & $\begin{array}{l}\text { Percentage } \\
\text { of cases }\end{array}$ \\
\cline { 2 - 3 } & $\boldsymbol{N}$ & Percentage & \\
\hline Entertainment & 88 & $20,7 \%$ & $71,5 \%$ \\
\hline News & 33 & $7,7 \%$ & $26,8 \%$ \\
\hline Social networks & 84 & $19,7 \%$ & $68,3 \%$ \\
\hline Email & 56 & $13,1 \%$ & $45,5 \%$ \\
\hline Games & 64 & $15,0 \%$ & $52,0 \%$ \\
\hline Medical applications & 41 & $9,6 \%$ & $33,3 \%$ \\
\hline Medical education & 31 & $7,3 \%$ & $25,2 \%$ \\
\hline Other & 20 & $4,7 \%$ & $16,3 \%$ \\
\hline None & 9 & $2,1 \%$ & $7,3 \%$ \\
\hline Total & 426 & $100 \%$ & $346,3 \%$ \\
\hline
\end{tabular}

If we consider only two types of mobile applications: medical applications and applications used for medical education, we can observe in Figure 6 that surprisingly, medical professionals use them more frequently than students. The main reasons that students said in the survey for that behaviour was not knowing these applications or not being needed to use them

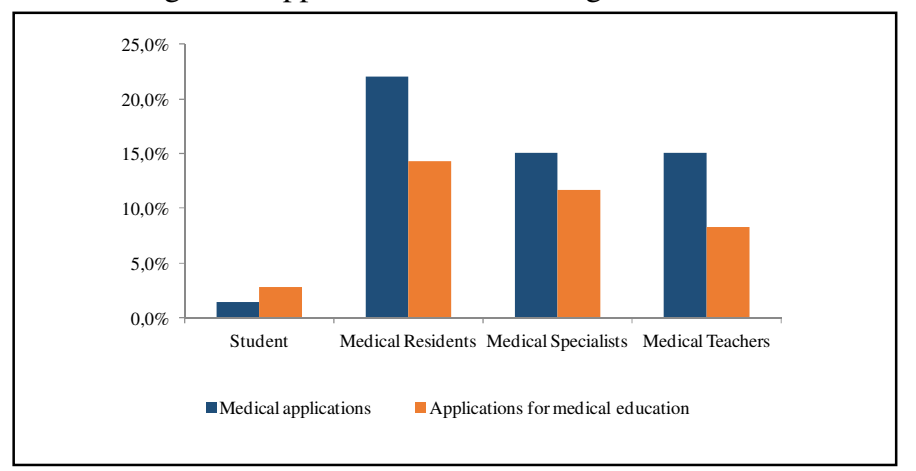

Fig 6. Percentage of participants selected any medical applications divided by profile.

\section{E. Number of mobile applications.}

The participants of the questionnaire answered as well what is the number of mobile applications that they downloaded from the last month. We considered only a short period of time in order to measure the activeness of the participants as it is more relevant they download an application one month ago than two years ago.

We calculate the mode in order to know the value that appears most often in the set of data. We obtain that for the number of applications used in Smartphone, the mode is between 1 and 10, whereas for tablets, the option selected the most was they do not use them.

We want to estimate the degree and correlation of relationship of these variables with the profile of the participants (students, medical residents, medical specialists and medical teachers). First of all, as we did with the frequency use variable, it is necessary to use non-parametric techniques. Therefore, we determine the Chi-Square statistic and Phi and Cramer's V value as well. The outcome results are presented in Table VI.

TABLE VI. RESULTS FOR CHI-SQUARE METHOD FOR NUMBER OF SMARTPHONE APPLICATION AND PROFILE OF THE PARTICIPANTS

\begin{tabular}{|l|l|c|}
\hline \multirow{2}{*}{} & \multicolumn{2}{|c|}{ Smartphone } \\
\cline { 2 - 3 } & \multicolumn{1}{|c|}{ Value } & $\boldsymbol{p}$ \\
\hline Chi-square & 13,176 & 0,040 \\
\hline Phi & 0,326 & 0,040 \\
\hline Cramer's V & 0,310 & 0,040 \\
\hline
\end{tabular}

TABLE VII. RESULTS FOR CHI-SQUARE METHOD FOR NUMBER OF TABLET APPLICATIONS AND PROFILE OF THE PARTICIPANTS

\begin{tabular}{|l|l|l|}
\hline \multirow{2}{*}{} & \multicolumn{1}{|c|}{ Tablets } \\
\cline { 2 - 3 } Chi-square & \multicolumn{1}{|c|}{ Value } & $\boldsymbol{p}$ \\
\hline Phi & 0,968 & 0,537 \\
\hline Cramer's V & 0,259 & 0,537 \\
\hline
\end{tabular}

Since the $p$-value is barely less than $0,05(p=0,04)$ there is enough evidence to reject the null hypothesis. The null hypothesis attempts to show that there is no relationship between the number of applications used with smartphones and the profile of the participants. Therefore, it is apparent from this table that there is a relationship between both variables. The value of Phi and Cramer's V coefficient falls within the range from 0 to 0,3 indicates that there is a weak relationship between them.

We performed the same analysis to set the outcome data but considering the variable for tablets. The data are presented in 
Table VII. In this case, the null hypothesis is that there is no relationship between the number of applications used with tablets and the profile of the participants.

At $\alpha=0,05$, the results above reveal that there is no enough evidence to fail to reject the null hypothesis $(p=0,537, p>0,05)$, that is there is a significance difference between both variables, so they can be considered independents.

\section{DISCUSSION}

These results provide important insights into the usage of mobile devices. The new technologies are part of our lives and it is a reality that we can avoid. These mobile devices can be used for higher education [14], but we do not know exactly how medical professionals are using them.

Other publications consider the significant potential of mobile technologies to be employed as powerful learning tools in higher education. However, their current use appears to be predominantly within a didactic, teacher-centred paradigm, rather than a more constructivist environment [15].

One of the limitations of this research study lies in the fact that the sample size was obtained only on Salamanca province, (Spain), but the surveys were distributed following the availability criteria (intentional or convenience sampling) [16]

A survey conducted by the General Medical Council demonstrated that $30 \%$ of doctors use a Smartphone for medical apps [17]. In our research study, we obtain than $33,3 \%$ of the participants approximately have downloaded and used medicalrelated applications and only $25,2 \%$ of them have used medical education applications. The main reasons that people reported were the unawareness of these types of applications and no necessity of using them. As it is published in [18] these apps have been available for years but there are still no data to both support their use and help us understand how best to use them.

\section{CONCLUSIONS}

This paper has investigated the usage of mobile device among medical students and professionals. The results of this research support the idea that the use of mobile devices is expected to grow and it can foster a richer learning experience. In general, therefore, it seems that the frequency use and number of applications used by the participants are different according to the profile of the participants if we consider applications for smartphones, but the results implies that this relationship does not exist if we analyse the applications for tablets.

This research also gives an approach of the role that students and medical professionals have on this industry. Their role of involvement in medical education will expand with the leadership of medical Schools incorporating the new technologies into their curriculums.
The use of medical apps are becoming more mainstream among medical professionals than undergraduate students what it reveals a clearly lack of awareness among students about them. It is important to point out that a strategy is needed for supporting education and providing an awareness- raising campaign about medical applications.

\section{ACKNOWLEDGMENT}

This research study has been made within University of Salamanca PhD Programme on Education in the Knowledge Society.

\section{REFERENCES}

[1] CMT. Informe Trimestral IV 2013. (2013) Comisión del Mercado de las Telecomunicaciones. www.cmt.es

[2] La sociedad de la Información en España 2013 (2014, Enero) Fundación Telefónica. www.fundacion.telefonica.com

[3] Dahlstrom, Eden, with a foreword by Charles Dziuban and J.D.Walkwer (2012, September). ECAR Study of Undergraduate Students and Information Technology, 2012. (Research Report). Louisville, CO: EDUCAUSE Center for Applied Research. Available from http://www.educause.edu/ecar.

[4] Tsinakos, A., \& Ally, M. (2013). Global mobile learning implementation and trends. Beijing, China: CRTVU Press.

[5] Dolan B, (2011). Nine medical schools that support mobile learning. Mobihealthnews. Retrieved from: http://mobihealthnews.com/12346/ninemedical-schools-that-support-mobile-learning/

[6] Gallegos A. (2013) Medical Schools Embrace Benefits of Tablets, Mobile Devices; Create New Ways of Learning. Association of American Medical College (AAMC) Reporter. Retrieved from https://www.aamc.org/newsroom/reporter/december2013/363858/mobil e-devices.html

[7] Briz, L., Juanes, JA, \& García, F.J. (2014) Analysis of Mobile devices as a support tool for professional medical education in the University School, EDULEARN14 Proceedings, pp. 4653-4658

[8] Ally, M. \& Prieto-Blázquez, J. (2014). What is the future of mobile learning in education? Mobile Learning Applications in Higher Education [Special Section]. Revista de Universidad y Sociedad del Conocimiento (RUSC). Vol. 11, No 1. pp. 142-151. doi http://doi.dx.org/10.7238/rusc.v11i1.2033

[9] EPOCRATES. (2013). Maximizin Multi-Screen Engagement Among clinicians (Research Report). Epocrates.

[10] Vinacua, B. V. (2007). Análisis estadístico con SPSS 14: estadística básica. McGraw-Hill Interamericana de España S.L.

[11] Lee, E. T., \& Wang, J. W. (2003). Statistical Methods for survival Data Analysis. En Statistical Methods for Survival Data Analysis (pp. i-xii). John Wiley \& Sons, Inc. Recuperado a partir de http://onlinelibrary.wiley.com/doi/10.1002/0471458546.fmatter/summar

[12] Chakravarti, Laha, and Roy, (1967). Handbook of Methods of Applied Statistics, Volume I, John Wiley and Sons, pp. 392-394

[13] Alan Agresti. (2002). Categorical Data Analysis (Second Edition.). New york: John Wiley \& Sons. Recuperado a partir de http://mathdept.iut.ac.ir/sites/mathdept.iut.ac.ir/files/AGRESTI.PDF

[14] Juanes JA, (2013) Using smartphones as tools for teaching innovation and training support. $2^{\mathrm{a}}$ Ed. JID. Universidad de Salamanca; pp: 111-116. ISBN: $10-84-695-8722-6$

[15] Herrington, J., herrington, A., Mantei, J., Olney, I. W., \& Ferry, B. (2009). using mobile tecnologies to develop new ways of teaching and learning. In J. Herrington, A. Herrington, J. Mantei, I. Olney, \& B. Ferry (Eds.), New 
L. Briz; J.A. Juanes; F. J. García Peñalvo - A systematic review of using mobile devices in medical education

technologies, new pedagogies: Mobile learning in higher education (pp. 114). Wollongong:Univeristy of Wollongong. Retrieved from http://ro.uow.edu.au

[16] McMillan, J.H., Schumacher, S.: Research in Education: A Conceptual Introduction, 5th ed. 2nd ed. Long-man, New York, NY (2001)

[17] Visser BJ, Bouman J (2012, April). There's a medical app for that. BMJ Careers . Retrieved from: http://careers.bmj.com
[18] Ozdalga, E., Ozdalga, A., \& Ahuja, N. (2012). The Smartphone in Medicine: A Review of Current and Potential Use Among Physicians and Students. Journal of Medical Internet Research, 14(5), e128. doi:10.2196/jmir.1994 